\title{
THREE-DIMENSIONAL EFFECTS OF MAXILLARY PROTRACTION ON PHARYNGEAL AIRWAY
}

\author{
Mai H. Aboulfotouh*, Khaled H. Attia ${ }^{* *}$ and Hanem Y. El-Feky***
}

\begin{abstract}
Introduction: patients with maxillary deficiency can exhibit reduced pharyngeal airway dimensions which can negatively affect the breathing efficiency of such cases.

Objective: the purpose of this study was to measure the changes in pharyngeal airway dimensions induced by maxillary protraction using facemask in a group of growing skeletal class III patients.
\end{abstract}

Materials and methods: 20 growing patients with ages ranging between 8-11 years and CVMI stages $1 \& 2$ were included in the study. Patients were diagnosed of skeletal class III malocclusion due to maxillary deficiency. All patients received facemask therapy as a treatment. CBCT scans were taken before the beginning of the treatment and by the end. The nasopharyngeal, oropharyngeal airway volumes and the minimum constricted area were measured using Dolphin software on CBCT scans.

Results: All the measured airway dimensions increased significantly after facemask therapy.

Conclusion: maxillary protraction induced by facemask treatment in young children was able to effect significant changes in the measured airway dimensions.

\section{INTRODUCTION}

Skeletal class III is considered one of the most challenging malocclusions to treat due to a number of factors. First, early diagnosis and intervention during the early mixed dentition or even in the deciduous dentition stage is often required in such cases. Furthermore, long term stability is only guaranteed if an adequate positive overjet and overbite were successfully achieved.

Skeletal class III malocclusion can exhibit a variety of etiological factors including deficient or retrusive maxilla, large or protrusive mandible, or a combination of these. Studies have shown that around two-thirds of the skeletal class III cases

\footnotetext{
* Lecturer of Orthodontics, Faculty of Dentistry, Cairo University.

** Professor of Orthodntics, Faculty of Dentistry, Cairo University.

*** Lecturer of Orthodontics, Faculty of Dentistry, Fayyoum University.
} 
are mainly due to maxillary hypoplasia alone or maxillary hypoplasia coupled with mandibular prognathism $^{(1,2)}$. Enlow (3) described the typical Class III individual as having a middle cranial fossa that is rotated in a backward and upward manner, resulting in the nasomaxillary complex being in a more retrusive position. Also forward rotation of the ramus is often encountered together with a vertically short nasal region. ${ }^{(1-5)}$.

Awareness of maxillary deficiency as all or part of the class III structural etiology, has led to the increased popularity of maxillary protraction appliances among which the facemask or the reverse pull head gear plays the leading role ${ }^{(6,7)}$.

Protraction facemask has gained wide popularity over the past decades, as it successfully demonstrated a significant orthopedic effect on the maxilla by continuous protraction and strain at the craniomaxillary sutures. The aim of these orthopedic approaches is to provide a more favorable environment for normal growth as well as an improvement in the occlusal relationship ${ }^{(8)}$. Several studies demonstrated the skeletal and dentoalveolar effects of maxillary protraction appliances, which were mainly the stimulation of the forward growth of the maxilla, redirection of the growth of the mandible into a more downward and backward rotation. This is also coupled with anterior and upward rotation of the palatal plane, protrusion of the upper incisors, and retrusion of the lower incisors ${ }^{(9-11)}$. While the dental and skeletal effects of the protraction facemask have been elaborated in many studies, its effect on the patients' airway dimensions was not investigated as much. Adequate pharyngeal size is important to guarantee that the patient gets a well sleep. Few studies highlighted the positive effect that maxillary protraction can induce on increasing the pharyngeal airway ${ }^{(12-16)}$. However, in all the studies, 2- dimensional lateral cephalograms were used for measuring the airway size and hence only the antero-posterior dimension of the airway was measured rather than the total volume of this space.
Thus, the purpose of this study was to investigate the effect of maxillary protraction facemask treatment on the airway dimensions using cone beam computed tomography in a group of growing children.

\section{MATERIALS AND METHODS}

This study was approved by the Research Ethics Committee, Faculty of Dentistry, Cairo University. All patients were informed about the study procedure and written informed consents were obtained from their parents.

\section{Subjects:}

This study was conducted on twenty patients presented at the out-patient clinic of the Department of Orthodontics, Faculty of Dentistry - Cairo University.

\section{Selection criteria}

- Growing patients with ages ranging from 8-11 years manifesting features of pre-pubertal cervical vertebrae maturational stages $1 \& 2$ (initiation $\&$ acceleration) assessed according to the method of Hassel \& Farman (1995) ${ }^{(17)}$ on the pre-treatment cone beam computed tomogram (CBCT).

- All patients possessed features of skeletal class III mainly due to maxillary deficiency as verified both clinically \& radiographically.

- Concave or flat facial profile.

- ANB angle $\leq 0^{\circ}$, SNA angle $\leq 80^{\circ}$

- Anterior cross bite or an edge to edge incisor relationship.

- Angle class III molar relationship.

- Presence of fully erupted maxillary first permanent molars. 


\section{Clinical procedure}

A Petit-type facemask (Ormco, USA) was used for every patient. Intraorally the facemask was attached to a fixed labiolingual appliance through extraoral elastics. The size of the elastics was individually selected for each patient as to provide $400 \mathrm{~g}$ of traction force per side. The direction of traction of the elastic pull was set as $30^{\circ}$ to the occlusal plane. The entire appliance assembly is shown in figure 1.

Instructions were given for the patients to wear the appliance 12-16 hours per day (afterschool hours and during sleep) and to take it off for meals and for sports. The patients were also instructed to change the elastics daily and whenever a loss of the elastic was experienced. The treatment continued for a period of 10 months.

\section{CBCT Imaging}

A cone-beam CT scan (i-CAT Next generation: imaging sciences international, Hatfield, PA) has been carried out for every patient before the start of the treatment and again after 10 months. The CBCT scans were done according to the following protocol:

Extended field of view (FOV) 17 x $23 \mathrm{~cm}$, voxel size $0.3 \mathrm{~mm}$. The patient's head was oriented with the Frankfurt Horizontal plane parallel to the floor and the mid-sagittal plane perpendicular to the floor. The patients were also instructed to bite on the previously prepared vacuum splint. CBCT scans were acquired in a Digital Imaging and Communications in Medicine (DICOM) format.

Axial images were imported in DICOM format into surgical planning software (Mimics, Materialize, Belgium) whereby coronal and sagittal reformatting was done, and a three-dimensional image was calculated. All the CBCT cuts were then segmented to separate the soft tissue from the underlying bony structures and only bone was selected. Three-dimensional reconstructed images were finally obtained on which all the three-dimensional skeletal and dental measurements denoting treatment changes after facemask were performed using the Mimics software.

\section{Airway volume analysis}

Three-dimensional pharyngeal airway measurements were done on CBCT scans using Dolphin 11.5 software (Dolphin Imaging and Management Solutions, Chatsworth, CA, USA) with a saturation level of 72. Descriptions of these measurements are listed in table 1 . The three-dimensional (3D) pharyngeal airway measurements included: (1) nasopharyngeal airway volume (figure 2), (2) oropharyngeal airway volume (figure 3), and (3) minimal constricted axial area (figure 4).

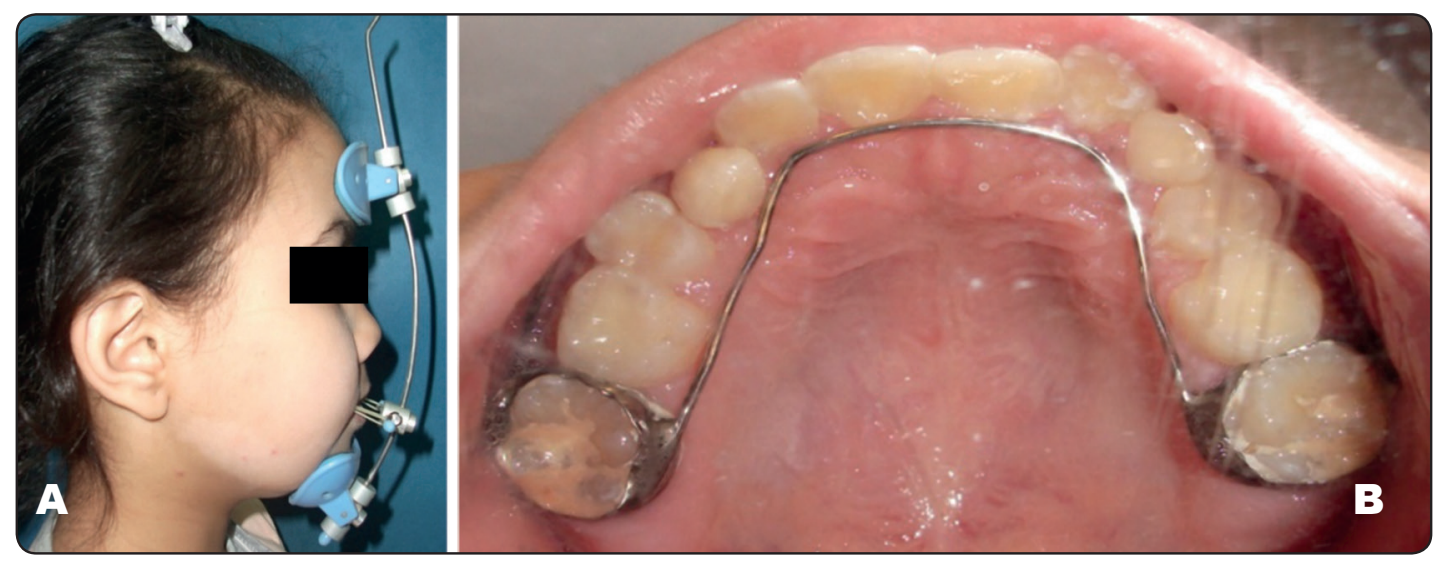

Fig. (1): A) Petit-type facemask in place. B) Intraoral component of the facemask ; the fixed labiolingual appliance. 
TABLE (1): Description of the three-dimensional airway analysis.

\begin{tabular}{|c|c|}
\hline $\begin{array}{l}\text { Naso-pharyngeal volume } \\
\text { (mm3) }\end{array}$ & $\begin{array}{l}\text { It is the volume between the following landmarks calculated from the software: } \\
\text { 1. The anterior border of nasopharynx: which is the plane connecting Pterygomaxillary points } \\
\text { (PTM) and posterior nasal spine (PNS). } \\
\text { 2. The inferior border: which is the plane perpendicular to the sagittal plane passing through } \\
\text { posterior nasal spine (PNS). } \\
\text { 3. The posterior border: which is the posterior wall of the pharynx. } \\
\text { 4. The lateral borders: which are the lateral walls of the pharynx. }\end{array}$ \\
\hline $\begin{array}{l}\text { Oro-pharyngeal volume } \\
\text { (mm3) }\end{array}$ & $\begin{array}{l}\text { It's the volume between the following landmarks calculated from the software: } \\
\text { 1. The superior border of Oropharynx: which is the plane perpendicular to sagittal plane } \\
\text { passing through posterior nasal spine (PNS). } \\
\text { 2. The inferior border: which is the plane perpendicular to sagittal plane passing through } \\
\text { inferior anterior point of third cervical vertebra C3. } \\
\text { 3. The anterior border: which is the soft palate, uvula, and tongue. } \\
\text { 4. The posterior border: which is the posterior wall of the pharynx, } \\
\text { 5. The lateral borders: which are the lateral walls of pharynx. }\end{array}$ \\
\hline $\begin{array}{l}\text { The minimal constricted } \\
\text { axial area }(\mathrm{mm} 2)\end{array}$ & The minimal constriction throughout the naso- and oropharyngeal airway area. \\
\hline
\end{tabular}

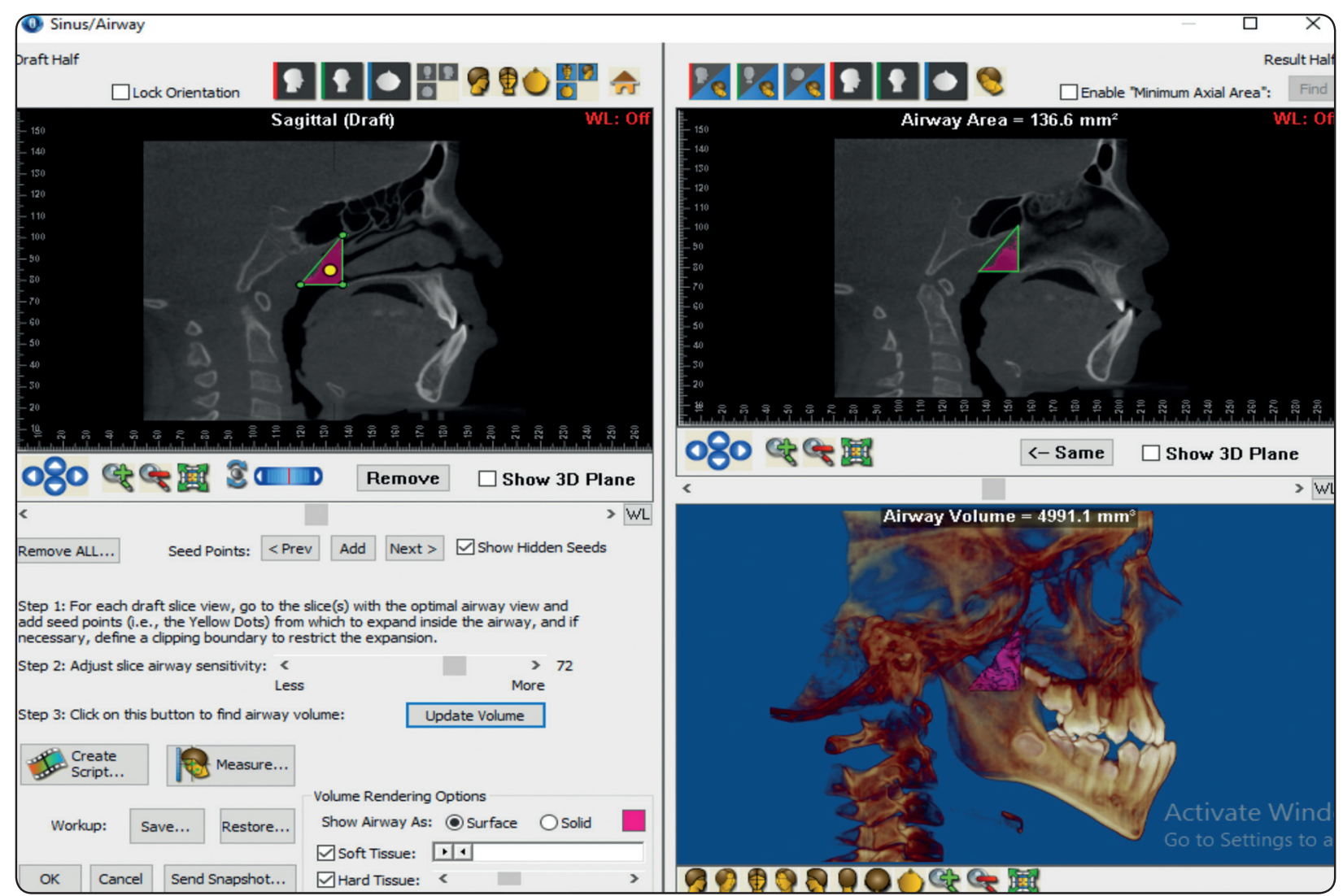

Fig. (2) Window of the Dolphin software showing the Nasopharyngeal airway volume. 


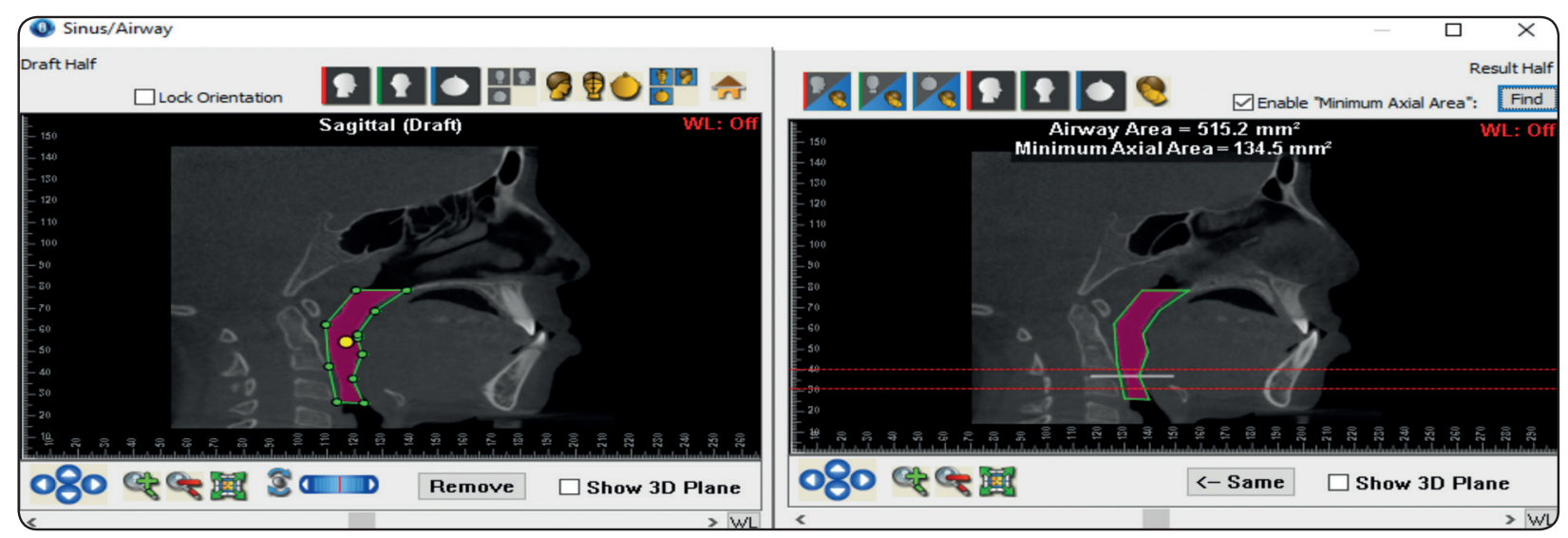

Fig. (3) Window of the Dolphin software showing the Oropharyngeal airway volume.

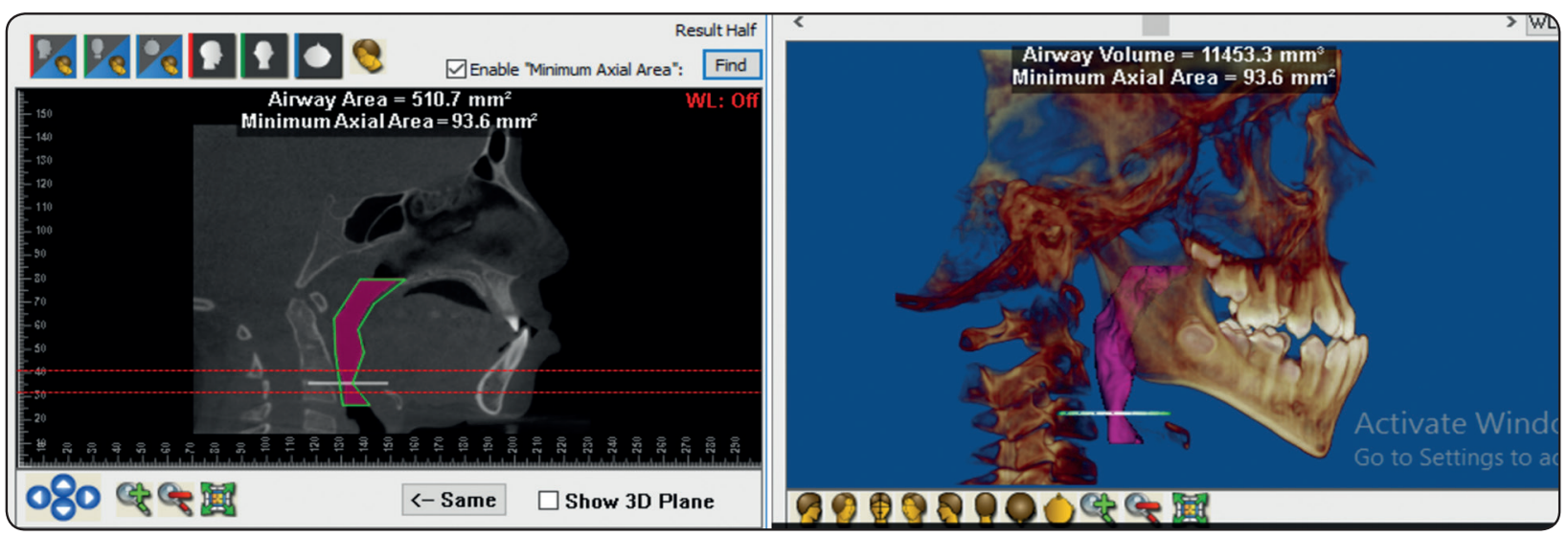

Fig. (4) Window of the Dolphin software showing the Minimum constricted area (marked by the white line).

All measurements were repeated by the same observer after 2 weeks to assess the intra-observer reliability.

\section{Statistical analysis}

Statistical analysis was performed with SPSS 16 (B) (Statistical Package for Scientific Studies), Graph pad prism \& windows excel. Data were presented as means and Standard deviations. Paired t-test was performed to compare between readings before and after treatment and the significance level was set at $\mathrm{P} \leq 0.05$. Interobserver reliability coefficient (Kappa test) was used to evaluate the agreement between two observations of the same assessor.

\section{RESULTS}

Intra-observer reliability coefficient (Kappa test) revealed almost perfect agreement $(\mathrm{IOC}>0.65)$ regarding nasopharyngeal, Oropharyngeal, and minimal constricted area as presented in table (2).

Significant skeletal changes took place after the facemask treatment which are shown in table 3 . Maxillary protraction was successfully achieved after facemask treatment as revealed by a significant increase in the SNA angle after treatment $(\mathrm{P} \leq 0.05)$. A significant rotation of the mandible in a downward and backward direction occurred after treatment as revealed by significant increases in the MP/SN and $\mathrm{NBa} / \mathrm{PtGn}$ angles. Moreover, the maxillary plane 
showed a significant anterior and upward rotation as evident from the significant decrease in the $\mathrm{SN} /$ PP angle.

Regarding the Airway volume measurements and the minimal constricted axial area, significant changes were revealed in all three measurements after treatment as presented in table 4. The nasopharyngeal airway volume (mean $\mathrm{mm}^{3}$ ) was $3145.28 \pm 969.31$ before treatment with facemask therapy then increased to $3930.85 \pm 907.18$ after treatment. In addition, the oropharyngeal airway volume $\left(\right.$ mean $\mathrm{mm}^{3}$ ) was $10027.80 \pm 2267.70$ before treatment with facemask therapy then increased significantly to $13184.19 \pm 2866.64$ after treatment, while the minimal constricted area (mean $\mathrm{mm}^{2}$ ) was $137.68 \pm 50.13$ before treatment with facemask therapy then increased to $202.27 \pm 64.34$ after treatment.

TABLE (2): Intra-observer reliability for airway measurement readings

\begin{tabular}{|c|c|c|}
\hline & IOC & Reliability \\
\hline Nasopharyngeal & 0.99 & Almost perfect \\
\hline Oropharyngeal & 1.00 & Almost perfect \\
\hline Min. constriction & 1.00 & Almost perfect \\
\hline
\end{tabular}

TABLE (3): Statistical analysis showing skeletal changes after facemask treatment

\begin{tabular}{|c|c|c|c|}
\hline \multirow{2}{*}{ Variable } & $\begin{array}{l}\text { Pre-treatment } \\
\qquad(\mathbf{n}=\mathbf{2 0})\end{array}$ & $\begin{array}{l}\text { Post-treatment } \\
\qquad(\mathrm{n}=\mathbf{2 0})\end{array}$ & \multirow[t]{2}{*}{ P-value } \\
\hline & Mean $\pm \mathrm{SE}$ & Mean \pm SE & \\
\hline $\operatorname{ANB}\left(^{\circ}\right)$ & $-1.8 \pm 0.5$ & $2.1 \pm 0.3$ & $0.048 *$ \\
\hline $\operatorname{MP} / \mathbf{P P}\left({ }^{\circ}\right)$ & $25.5 \pm 1.3$ & $26.5 \pm 1.4$ & $0.008 *$ \\
\hline $\mathrm{SN} / \mathrm{MP}\left(^{\circ}\right)$ & $36.5 \pm 1.2$ & $38.3 \pm 1.4$ & $0.034 *$ \\
\hline SNA $\left(^{\circ}\right)$ & $78.6 \pm 1.3$ & $81.7 \pm 1.2$ & $0.045^{*}$ \\
\hline $\mathrm{SNB}\left({ }^{\circ}\right)$ & $81.3 \pm 1.4$ & $79.9 \pm 1$ & 0.825 \\
\hline $\mathrm{NBa} / \operatorname{PtGn}\left({ }^{\circ}\right)$ & $86.3 \pm 0.8$ & $84.7 \pm 0.8$ & $0.004 *$ \\
\hline SN/PP $\left(^{\circ}\right)$ & $11.5 \pm 0.7$ & $10.1 \pm 0.9$ & $0.002 *$ \\
\hline
\end{tabular}

\section{DISCUSSION}

A reduction in the vertical height of the nasal region is often encountered in skeletal class III maxillary deficiency cases ${ }^{3,4)}$. Application of maxillary protraction appliances can produce good results in patients having skeletal Class III malocclusion due to maxillary deficiency, causing the maxilla and maxillary teeth to move forward and the mandible to move backward ${ }^{(18)}$. Several studies demonstrated that reverse headgear treatment stimulated the forward displacement of the maxilla and reduced the forward displacement of the mandible ${ }^{(10,19,20)}$.

Early treatment is commonly indicated in such

TABLE (4): Statistical analysis of Airway measurements after facemask treatment.

\begin{tabular}{|c|c|c|c|c|c|c|}
\hline \multirow{2}{*}{} & \multirow{2}{*}{$\mathrm{N}$} & \multicolumn{2}{|c|}{ Before } & \multicolumn{2}{|c|}{ After } & \multirow{2}{*}{ P value } \\
\cline { 3 - 6 } & & $\mathrm{M}$ & $\mathrm{SD}$ & $\mathrm{M}$ & $\mathrm{SD}$ & \\
\hline Nasopharyngeal $\mathrm{mm}^{3}$ & 20 & 3145.28 & 969.31 & 3930.85 & 907.18 & \multirow{2}{*}{$0.018^{*}$} \\
\hline Oropharyngeal $\mathrm{mm}^{3}$ & 20 & 10027.80 & 2267.70 & 13184.19 & 2866.64 & $0.004^{*}$ \\
\hline Min. constriction $\mathrm{mm}^{2}$ & 20 & 137.68 & 50.13 & 202.27 & 64.34 & $0.0011^{*}$ \\
\hline
\end{tabular}

M; mean

$N$; total count
$S D$; standard deviation

*significant level 
cases ${ }^{(15)}$. Prepubertal children with age range of 8-11 years were included in this study based on their cervical vertebrae maturational indicators where they possessed CVMI stages 1 or 2. A matched control group with the same malocclusion was not added to the current study as it was thought to be unethical to deny the patients the privilege of early intervention in such a particular condition.

Most of the studies ${ }^{(12,13,16,21)}$ examined the changes in the airway dimensions using lateral cephalometric radiographs. This method had the limitation of being a 2-dimensional assessment of a three-dimensional structure. Therefore, it was only possible to measure the anteroposterior dimension of the airway using lateral cephalometric radiographs rather than providing a volumetric evaluation of the space.

In the current study, we investigated the effects of protraction facemask treatment on the nasopharyngeal and oropharyngeal airway volumes and the minimum constricted area in a group of growing patients with skeletal class III and maxillary deficiency using three-dimensional CBCT imaging.

Many studies investigated the correlation between the maxillary protraction appliances and the pharyngeal airway. Oktay and Ulukaya ${ }^{(13)}$ declared an increase in the size of the airway after maxillary protraction. Likewise a study by Hiyama et al. ${ }^{(12)}$ found that maxillary growth induced by protraction treatment had a significant positive effect on the superior airway dimension. Based on their findings, they suggested that stimulating maxillary growth in growing patients could improve the respiratory function of patients with maxillary hypoplasia. Akin et al. ${ }^{(21)}$ reported an increase in the orofacial airway dimensions after facemask therapy in children. Moreover, the long term positive effect of the facemask therapy on the airway dimensions was successfully maintained for a 4 year follow-up period after the treatment in a study by kaygisiz et al. ${ }^{(15)}$. Maxillary protraction accompanied by maxillary expansion were also able to induce improvement in the oro- and naso-pharyngeal airway dimension in the short term as proved by Kilinc et al. ${ }^{(16)}$ and Ucar et al. ${ }^{(21)}$. Those results were compatible with the results of the current study where an increase in the oropharyngeal, nasopharyngeal airway volumes was achieved together with a significant increase in the minimum constricted area after maxillary protraction using Facemask appliance.

In this study, a statistically significant increase in SNA was observed after the facemask treatment. Although there was a reduction in the SNB after treatment, this change was not statistically significant. In fact, the decrease in SNB was not related to the inhibition of mandibular growth but occurred as a result of clockwise rotation of the mandible as evident from the statistically significant increase in the mandibular plane angle (MP/SN) as well as in the facial axis angle ( $\mathrm{NBa} / \mathrm{PtGn})$.

Clockwise Rotation of the mandibular plane can be also attributed to the rotation of the maxillary plane in a counterclockwise direction, with posterior nasal spine moving inferiorly more than anterior nasal spine. This was evident in the current study as revealed by the significant decrease in the SN/PP angle after facemask treatment. Same results were also documented in previous studies by Mermigos et al. ${ }^{(7)}$, Takada et al. ${ }^{(22)}$ and Turley et al. ${ }^{(23)}$.

In view of the results of the current research, the oro- and Naso-pharyngeal airway volumes together with the minimum constricted area were significantly increased secondary to the maxillary protraction as well as the mandibular clockwise rotation that was induced by the facemask treatment.

\section{CONCLUSIONS}

1. Successful maxillary advancement was achieved by the protraction facemask appliance.

2. Maxillary advancement resulted in a significant increase in the Nasopharyngeal, Oropharyngeal airway volumes as well as in the minimal constricted axial area. 


\section{REFERENCES}

1. Guyer EC, Ellis EE, McNamara JA, Behrents RG. Components of class III malocclusion in juveniles and adolescents. Angle Orthod. 1986.

2. Ellis E, McNamara JA. Components of adult class III malocclusion. J Oral Maxillofac Surg. 1984.

3. Dean D. Facial growth, 3rd ed. By D. H. Enlow. Philadelphia: W. B. Saunders. 1990. 576 pp. $\$ 79.00$ (cloth). Am J Phys Anthropol. 1991.

4. Williams S, Andersen Aarhus CE. The morphology of the potential Class III skeletal pattern in the growing child. Am J Orthod. 1986.

5. Jacobson A, Evans WG, Preston CB, Sadowsky PL. Mandibular prognathism. Am J Orthod. 1974.

6. Cozzani G. Extraoral traction and Class III treatment. Am J Orthod. 1981.

7. Mermigos J, Full CA, Andreasen G. Protraction of the maxillofacial complex. Am J Orthod Dentofac Orthop. 1990.

8. Campbell PM. The dilemma of Class III treatment. Early or late? Angle Orthod. 1983.

9. Ngan P, Hägg U, Yiu C, Merwin D, Wei SH. Soft tissue and dentoskeletal profile changes associated with maxillary expansion and protraction headgear treatment. Am J Orthod Dentofacial Orthop. 1996.

10. Baccetti T, McGill JS, Franchi L, McNamara JA, Tollaro I. Skeletal effects of early treatment of Class III malocclusion with maxillary expansion and face-mask therapy. Am J Orthod Dentofacial Orthop. 1998.

11. Sung SJ, Baik HS. Assessment of skeletal and dental changes by maxillary protraction. Am J Orthod Dentofacial Orthop. 1998.

12. Hiyama S, Suda N, Ishii-Suzuki M, Tsuiki S, Ogawa M, Suzuki S, et al. Effects of Maxillary Protraction on Cra- niofacial Structures and Upper-Airway Dimension. Angle Orthod. 2002.

13. Oktay H, Ulukaya E. Maxillary protraction appliance effect on the size of the upper airway passage. Angle Orthod. 2008.

14. Mohammed H, Bigazzi AY, Sayed T. Characterization of bicycle following and overtaking maneuvers on cycling paths. Transp Res Part C Emerg Technol. 2019.

15. Kaygsz E, Tuncer BB, Yüksel S, Tuncer C, Yildiz C. Effects of maxillary protraction and fixed appliance therapy on the pharyngeal airway. Angle Orthod. 2009.

16. Kilinç AS, Arslan SG, Kama JD, Özer T, Dari O. Effects on the sagittal pharyngeal dimensions of protraction and rapid palatal expansion in Class III malocclusion subjects. Eur J Orthod. 2008

17. Hassel B, Farman AG. Skeletal maturation evaluation using cervical vertebrae. Am J Orthod Dentofac Orthop. 1995.

18. Uçar F, Öztürk M, Ramoglu S, Sari Z. Effects of maxillary expansion rate on the nasopharyngeal airway in the mixed dentition. J Orthod Res. 2013.

19. Gallagher RW, Miranda F, Buschang PH. Maxillary protraction: treatment and posttreatment effects. Am J Orthod Dentofacial Orthop. 1998.

20. Arman A, Toygar TU, Abuhijleh E. Evaluation of maxillary protraction and fixed appliance therapy in Class III patients. Eur J Orthod. 2006.

21. Akin M, Ucar FI, Chousein C, Sari Z. Effects of chincup or facemask therapies on the orofacial airway and hyoid position in Class III subjects. J Orofac Orthop. 2015.

22. Takada K, Petdachai S, Sakuda M. Changes in dentofacial morphology in skeletal Class III children treated by a modified maxillary protraction headgear and a chin cup: A longitudinal cephalometric appraisal. Eur J Orthod. 1993.

23. Turley PK. Orthopedic correction of Class III malocclusion: retention and phase II therapy. J Clin Orthod. 1996. 